\title{
Runaway sexual minority youth: Comparative analysis using Bronfenbrenner and Foucault
}

\author{
Marcus Crawford ${ }^{1}$
}

The problem of runaway youth and homelessness poses significant challenges to professionals who work with at-risk populations. Sexual minority youth (SMY) are at increased risk of both running away and homelessness. When working with homeless SMY, professionals should utilize a theoretical base. Ecological System perspective provides a guide to examine the myriad systems of an individual's life. Foucault conceived stigma through the prism of power/knowledge structures that dominate social control and normalization values over society. The concepts of Ecological Systems from Bronfenbrenner and Stigma as conceptualized by Foucault offer a lens through which this social problem may be addressed. [Article copies available for a fee from The Transformative Studies Institute. E-mail address: journal@transformativestudies.org Website: http://www.transformativestudies.org (02018 by The Transformative Studies Institute. All rights reserved.]

KEYWORDS: Bronfenbrenner, Foucault, Ecological Systems, Stigma, Sexual Minority.

Because most people have never been homeless or lived on the streets, the problem of youth homelessness and running away can be difficult to conceptualize. As such, when working with runaway youth, professionals best practice from a theoretical base. Bronfenbrenner's (1979) Ecological Systems theory is well-known in the social work domain; however, it is often not applied beyond the microsystem level. Stigma is typically linked to Goffman's (1963) formulation without consideration of the larger societal infrastructure behind the creation and use of stigma. In order to examine stigma in this way, the concept of

\footnotetext{
${ }^{1}$ Marcus Crawford, MSW, is a third-year Ph.D. candidate in the School of Social Work at the University of Texas at Arlington. His research includes a focus on youth in the foster care and juvenile justice systems, youth at-risk for adverse outcomes, and youth emerging into adulthood. Prior to entering his Ph.D., Marcus worked for nearly 15 years in the child welfare system, primarily focusing on older youth who were aging out of the system.
} 